\title{
Tréplica: Quem Tem Medo do Fazer Acadêmico enquanto Práxis?
}

\author{
Maria Ceci Misoczky \\ Jackeline Amantino-de-Andrade
}

A ação de debater, na nossa concepção, se refere à expressão de idéias, organizadas em argumentos, a respeito de um tema. O argumento que desenvolvemos em nosso artigo expressa posições sobre o fazer crítica no nosso contexto de vida e atuação profissional, argumentando que a categoria da emancipação e a adoção de um princípio material de afirmação da vida podem ser referências para a ação política que visa transformar o sistema presente e construir uma nova ordem, na qual a vida das vítimas venha a se tornar possível.

Neste argumento a distinção entre pragmatismo e práxis exercia um papel central. Como parece haver algum esquecimento com relação ao conceito de práxis, não custa recordá-lo antes de ir adiante. Na ciência funcional prática é a aplicação da teoria, é a utilização da teoria para manipular objetos (incluindo sujeitos objetificados). Nela a teoria só tem sentido se for passível de aplicação. Já a teoria crítica, dialeticamente, nega o mundo naturalizado pela ciência funcional para mostrar que esta não cumpre com os ideais políticos que a sustentam - a liberdade e a igualdade, ao materializar um sistema contraditório com esses ideais. Na teoria crítica a teoria mostra como as coisas são, e na prática como elas deveriam ser. A práxis não é uma aplicação da teoria, mas - segundo a influência de Kant - um conjunto de ideais, de princípios, que orientam a ação no mundo. Daí decorre a essência da teoria crítica: compreender o mundo que é a partir do que ele pode ser; e ver, na realidade, o que impede a concretização dessa outra configuração. Trata-se, portanto, de apresentar o mundo como ele é, com suas tendências à reprodução de estruturas e obstáculos à emancipação, e também considerar as tendências potenciais de ação para a transformação dessas estruturas e a superação desses obstáculos. A práxis é ciência enquanto trabalho (apropriação do real), e trabalho material enquanto ação transformadora da história.

Ainda retomando nosso próprio artigo, afirmamos que se trata de um "texto para provocar e estimular o embate e o contraditório num debate aberto e franco em torno do tema da crítica”. Expressamos, naquele momento, uma concepção ingênua. Além disso, ao colocar as questões que, esperávamos, poderiam desencadear uma agenda de debates sobre a ação política no campo científico da administração no Brasil, desconsideramos a relevância de contextualizá-las aos tempos da globalização. O artigo do Professor Alexandre Faria nos oferece a oportunidade de retomar essas evidentes insuficiências do nosso texto. 
O Prof. Alexandre nos oferece uma linha de argumentação em torno da emergência / inserção da crítica na academia anglo-americana no contexto da globalização. Mais especificamente, reflete sobre as funções do conhecimento em administração para as elites dos países desenvolvidos e alerta para os riscos de isolamento decorrentes da prática da crítica no mundo da academia. Trataremos desses temas trazendo-os para uma reflexão sobre nossas próprias práticas e assumindo o campo científico em que nos encontramos como uma arena de luta. Aqui, já se deduz, nos socorreremos das inspirações de Pierre Bourdieu (1976).

Um campo científico se estrutura em torno da luta pela autoridade científica, um tipo particular de capital social que assegura um poder sobre os mecanismos constitutivos do campo. A luta na qual cada um dos atores se envolve, para impor o valor de seus produtos e de sua própria autoridade de produtor legítimo, tem sempre em jogo o poder de definir o que é ciência - a delimitação do campo dos problemas, dos métodos e das teorias que podem ser consideradas científicas. Assim, os dominantes são aqueles que conseguem impor a definição de ciência segundo a qual a realização mais acabada da mesma consiste em ter, ser e fazer, o que eles têm, são e fazem. Na medida em que a própria definição dos critérios de julgamento e dos princípios de hierarquização é objeto de uma luta, ninguém é bom juiz, porque não há bom juiz que seja juiz e parte (BOURDIEU, 1976).

A forma como se reveste a luta, inseparavelmente científica e política, pela legitimidade depende da estrutura de distribuição do capital específico de reconhecimento científico entre os participantes na luta. Em todo campo se opõem, com forças mais ou menos desiguais segundo a estrutura de distribuição do capital científico, os dominantes e os recém chegados. Os dominantes estão destinados a estratégias de conservação, para assegurar a perpetuação da ordem científica estabelecida a qual pertencem.

"Segundo a posição que ocupam na estrutura do campo [...], os recém chegados podem se orientar para colocações seguras de estratégias de sucessão, adequadas para assegurar-lhes, nos termos de uma carreira previsível, os benefícios prometidos aos que realizam o ideal oficial da excelência científica ao preço de inovações circunscritas aos limites autorizados; ou podem se orientar por estratégias de subversão, colocações infinitamente mais custosas e mais arriscadas, que não podem assegurar os benefícios prometidos aos detentores do monopólio da legitimidade científica, se não ao preço de uma redefinição completa dos princípios de legitimação da dominação" (BOURDIEU, 1976, p. 97). 
Os sustentadores da ordem estabelecida exaltam a quantificação, a formalização, a objetividade e a neutralidade ética. É através da retórica da cientificidade que a comunidade dominante produz a crença no valor de seus produtos e na autoridade de seus membros. Essa estratégia ideológica, disfarçada de posicionamento epistemológico (BOURDIEU, 1976), é o meio através do qual os ocupantes de uma posição determinada justificam sua própria posição e as estratégias que colocam em prática para mantê-la e melhorá-la, ao mesmo tempo que a utilizam para desacreditar os que expressam posições opostas e suas estratégias.

Não restam dúvidas que aqueles que se alinham com as ideologias dominantes, na defesa de suas posições no campo, se encontram em uma condição privilegiada.

"Assumindo uma atitude positiva para com as relações de produção dominantes, podem contar, em suas confrontações ideológicas, com o apoio das principais instituições econômicas, culturais e políticas do sistema todo. Ao mesmo tempo, visto que se identificam 'interiormente', digamos assim, com os processos contínuos de reprodução socioeconômica e político-ideológica, podem estipular a 'praticabilidade' como pré-requisito absoluto para a avaliação da seriedade ou inadmissibilidade categórica da crítica, bem como a legitimidade da mudança social. Assim, não é acidental que as ideologias dominantes insistam nas insuperáveis virtudes do 'pragmatismo' e da 'engenharia social gradual', rejeitando (no mais das vezes, pela simples atribuição de algum rótulo exorcizante) todas as formas de 'síntese total' ou de 'holismo' - isto é, nas palavras autoconfiantes de suas figuras representativas, qualquer concepção de ordem social 'radicalmente diferente daquela estabelecida'.

Além disso, dada sua posição privilegiada na ordem social prevalecente, elas podem ditar as condições e regras gerais do próprio discurso ideológico" (MÉSZÁROS, 2004, p. 233).

O recurso a estes autores militantes ajuda a compreender que alguns atores do nosso campo científico não adotem a estratégia da sucessão como orientadora da sua inserção. Ajuda a entender que não é possível "politizar demais a academia”, como menciona o Prof. Alexandre, já que essa, enquanto campo de poder é, por natureza, absolutamente politizada. Também ajuda a perceber que, na luta, o consenso não é só difícil, como é impossível e indesejável.

Considerar o campo científico da administração, no Brasil, como um espaço de contradições e de estratégias de preservação e disputa permite contextualizar uma "censura" que tem sido expressa de modo recorrente. Em pelo menos um debate no ENANPAD, no texto do Prof. Clóvis no site da ANPAD, e nos textos 
de Alcadipani e Faria, se encontram a censura, ainda que disfarçada, ao que é identificado como "prescrição". Pode-se supor, talvez ingenuamente, que por vivermos em um campo dominado por prescrições, não habituados ao debate político de idéias, não sejamos capazes de reconhecer o que nos é estranho. Pode ser... Mas pode ser também que a acusação de prescrição se refira à atitude herética de expressar claramente posições ideológicas. Voltaremos a isso mais adiante.

Aqui é relevante tratar a configuração organizacional do campo da administração no Brasil. Não consideramos que seja adequado descrevê-lo como sendo composto por escolas de negócio. O ensino e a pesquisa da administração no Brasil tem uma forte referência à administração pública e, mais recentemente, à gestão social (como nos lembra muito adequadamente Alcadipani). Nós duas, por exemplo, exercemos nossas atividades em instituições públicas de ensino. Uma de nós tem uma trajetória de mais de duas décadas como militante no campo da saúde coletiva, e continua a exercer essa militância na Escola de Administração da UFRGS, que se constitui em um espaço extremamente propício para o apoio ao desenvolvimento da gestão em saúde considerando os princípios políticos do direito social e da universalidade. A outra tem uma trajetória como socióloga, uma tese de doutorado em administração posicionada sobre o problema do trabalho infantil, e hoje é pesquisadora do Observatório da Realidade Organizacional na UFPE, que toma como uma de suas preocupações a crítica à mercantilização de organizações culturais. Nenhuma de nós trabalha com negócios, mas trabalhamos, sim e intensamente, com administração.

Essa constatação talvez ajude a compreender a tranqüilidade com que expressamos nossas posições. Não estamos em busca de distinção no campo científico da administração no Brasil, mas também não nos colocamos à sua margem. Nos colocamos firmemente como constituintes desse campo e como ativas nas lutas que nele se travam. Nossa conviç̧ão, nesse contexto, é que a condenação não é ao que expressamos, mas ao ato político de fazê-lo. O que incomoda e gera reações é a perigosa atitude de autenticidade e transparência, é assumir valores e posições ético-ideológicas, é não se esconder sob o mito da neutralidade científica para fugir de responsabilidades políticas, é esse sinal de desafio à ordem existente e aos parâmetros que estruturam sua reprodução. O que incomoda é tomarmos o fazer acadêmico como práxis; é realizarmos a "subversão herética" de explorar a possibilidade de mudar o mundo social modificando a representação desse mundo, "opondo uma pré-visão paradoxal (utopia, projeto, programa) à visão comum que apreende o mundo social como mundo natural" (BOURDIEU, 1996, p. 118). 
Queremos refletir sobre um outro aspecto do argumento do Prof. Alexandre: o tema da globalização e do movimento cultural. É importante fazer essa interligação, pois, como bem nos lembra Bourdieu, a globalização é uma doxa com grande força simbólica. É um conjunto de crenças que produz consenso através de estruturas subjetivas (formas simbólicas) e estruturas objetivas (objetos simbólicos). Nesse processo, corre-se o risco de que predomine uma visão de mundo que naturaliza o mercado como centro ordenador de todas as relações sociais e, assim, se aceita uma dominação que subjuga a todos. Entretanto, é possível ver a globalização de diferentes formas.

Recorrendo-se a Latour e cia., se pode acreditar que outras vozes podem ordenar o mundo social, articulando-se em translações. Diferente da difusão e determinação de conteúdos de um centro para as partes periféricas, na translação um centro é enucleado pela associação de forças sempre referidas a contextos. Neste processo, diferentes vozes se articulam para criar ordenações parciais para o mundo social que se quer e se pode enunciar, associando elementos heterogêneos, em diferentes escalas, que estão abertos a contínuas transformações em um jogo de correlação de forças. Assim, acreditamos que uma outra ordenação é possível, inclusive sob a égide da globalização, basta transladarmos nossas vozes, periféricas e excluídas, e construir outros enunciados, mesmo que parciais - afinal vivemos a história, por meio da formação de redes, de teias que se estendem e se fortalecem. Portanto, entendemos que o movimento cultural, neste início de século, não se limita a uma oposição ao estrangeiro, mas, fundamentalmente, em transladar outros enunciados sobre a ordenação do mundo social, tornando-os fortes pela contínua agregação de aliados, de maneira a permitir uma socialização maciça desses conteúdos.

Canclini (2003) afirma que os conhecimentos disponíveis sobre a globalização constituem um conjunto de narrativas, obtidas por meio de aproximações parciais e divergentes, em muitos pontos. Segundo esse autor, essa precariedade costuma se ocultar por meio de duas operações. Uma consiste em reduzir a globalização a um ponto de partida pretensamente inquestionável, acima das ideologias, que estabelece um modelo único para países desenvolvidos e subdesenvolvidos que não queiram ficar fora da economia mundial. A outra posição é a daqueles que, de acordo com o princípio pós-moderno que aceita a redução do saber à coexistência de múltiplas narrativas, abdicam da busca de um referencial interculturalmente compartilhado que organize alguns enunciados básicos. Canclini (2003, p. 44) defende, então, a necessidade de investigar o que representa aquilo que a globalização exclui para se constituir. Para tanto, propõe que a globalização seja tratada como "um conjunto de processos de homogeneização e, ao mesmo 
tempo, de fragmentação articulada do mundo, que reordenam as diferenças e desigualdades sem suprimi-las”.

Como nos colocarmos nesse cenário? O Prof. Alexandre Faria (2003), em um outro texto, nos dá a indicação: pela constante vigilância, pela reflexividade. Precisamos estar alerta para distinguir entre a rica convivência entre múltiplas tradições culturais que se reconhecem mutuamente e a unificação por anexação, bem como para a adoção não reflexiva de modelos das nações dominantes: sejam modelos para nossas organizações de ensino e pesquisa, sejam modelos de ensino e de pesquisa, sejam referenciais teóricos.

Antes de encerrar queremos retomar alguns pontos que, no nosso entendimento, ainda precisam continuar sendo explorados, pelo menos por aqueles que acreditam que o fazer em administração não precisa se confinar a reproduzir o mundo que ela mesma ajudou a criar. Afinal, vamos encarar nossas dificuldades e potencialidades para a ação política no nosso campo de inserção e no enfrentamento dos problemas da nossa formação social, ou continuaremos nos refugiando em referenciais confortáveis - como a saída cor de rosa da microemancipação. Podemos refletir sobre nosso campo científico e as ações que o produzem e reproduzem, ou preferimos olhar para os campos científicos de outros países? A busca de saídas fáceis pode dar a impressão que estamos avançando. Será que, em vez disso, não estamos assumindo a repressão(1) das nossas potências? Para avançar precisamos parar de fingir que nos movemos sem expressar posições ideológicas e, de preferência, precisamos abandonar também ambigüidades ideológicas. Essa atitude pode perturbar o mito da academia, com seus debates assépticos e polidos, como a torre de marfim que não se contamina com as mazelas do mundo.

Aliás, nada mais conveniente para perpetuar essa configuração do que a defesa da verdade única da pluralidade absoluta. Cabe lembrar que o pluralismo, quando se torna uma ideologia, relativiza a legitimidade da contestação feita do ponto de vista daqueles que são estruturalmente subordinados. No cenário pós-político da multiplicidade de perspectivas, a função da ética passa a ser meramente garantir o espaço de neutralidade em que tal diversidade possa coexistir pacificamente. Será que a tarefa política de hoje não é exatamente romper com a construção ideológica do pluralismo absoluto? Em tempos de pós-política, onde se afirma que a era das ideologias terminou e que toda posição é igualmente legítima, a ação política por natureza não será questionar a verdade única do pluralismo total?

Finalmente, é indispensável registrar o significado de que esse debate se realize nas páginas da Revista de Administração Contemporânea. Essa é uma evidência 
de que o campo científico da administração no Brasil é capaz de problematizarse, se assumir a reflexividade como prática entre seus constituintes. Isso não significa que as diferenças sejam borradas e que cheguemos a um mítico porto de encontro e consenso. Nesse espaço se evidencia que a contradição e o debate aberto de posições ideológicas não constituem qualquer ameaça à tradição do livre pensar. Muito pelo contrário, constituem sua mais qualificada expressão.

\section{Not A}

\footnotetext{
${ }^{1}$ No sentido freudiano ou em qualquer sentido que o leitor adotar.
}

\section{ReferênCias Bibliográficas}

\section{BOURDIEU, P.}

Le champ scientifique. Actes de la recherce en sciences sociales,v. 2, n. 3, p. 88-104, 1976.

\section{A economia das trocas} lingüísticas. São Paulo: EDUSP, 1996.

CANCLINI, N. G.

A globalização imaginada. São Paulo: Iluminuras, 2003.
FARIA, A.

Pesquisa em redes estratégicas: descobertas e reflexões etnográficas. Revista de A d m i n i s t $r$ a ç ã o Contemporânea, Fórum II ENEO, p. 11-23, 2003.

MÉSZÁROS, I.

O poder da ideologia. Campinas: Boitempo Editorial, 2004. 